\title{
Alveolar Bone Biology in Extrusion Splint Technique
}

\author{
Sharma P, Shankar TP
}

Department of Periodontics

CODS, BPKIHS

Corresponding Author

P Sharma

Dental surgeon

Department of Periodontics CODS, BPKIHS

Email: prerana222@hotmail.com

Citation

Sharma P, Shankar TP. Alveolar Bone Biology in Extrusion Splint Technique. Kathmandu Univ Med J 2012;39(3):6669.

\begin{abstract}
The moment after the tooth avulsion, blood supply to the pulp is interrupted and the periodontal ligament cells are exposed to injury from the external environment. Complete healing is possible if the tooth can be immediately replanted and favorable environment is created.A case of report of intruded and mobile upper left central incisor due to Road Traffic Accident of a twenty-two-year-old patient is presented here. In which, intentional extrusion traumatized tooth and then flexible acrylic wire splinting was done to stabilize it. Previously there was no periapical bone support but with nine months maintenance follow up bone has shown a significant improvement towards healing.
\end{abstract}

\section{KEY WORDS}

Traumatized tooth, extrusion, intrusion splint, acrylic wire splint

\section{INTRODUCTION}

The word trauma implies a reasonable severe, nonphysiological lesion to any part of the body. Any thermal, chemical or mechanical lesion that affects the dentition should be analyzed as dental trauma and its effect, as traumatic dental injury. ${ }^{1}$ Violence, road traffic accidents and sports activities have been identified as some of the major causes of dental trauma. ${ }^{2}$ Injury can lead to displacement, rotation, intrusion and/or fracture of teeth. ${ }^{3}$ Avulsion and luxation are complex injuries that affect multiple tissues accounting for up to $16 \%$ of all traumatic injuries in the permanent and $7-21 \%$ of injuries in the primary dentition. ${ }^{4-9}$ Traumatic teeth can be treated in different ways, in the WHO system, eight groups were classified according to anatomical structures involved. ${ }^{10,11}$ Splinting, as a treatment modality for traumatized teeth after avulsion or luxation, is recommended. ${ }^{12}$

Replantation of teeth is the surgical method of positioning of teeth back in its original place in the sockets. One of the modifications in simple replantation is extrusion of tooth which was intruded due to trauma and splint to stabilize in its relatively new position. This newer technique modification of replantation where there is induced extrusion and stabilization by splinting is called an extrusion splint. In this paper we will be discussing this newer technique of extrusion splint and the favorable healing environment provided by the surrounding alveolar bone in adequate nine months follow up.

\section{CASE REPORT}

Male patient aged 22 years reported to emergency of BPKIHS (B.P. Koirala Institute of Health Sciences, Dharan, Nepal), due to Road Traffic Accident assaulted by motorbike with cut on upper lip, laceration of check, lip and mobility of teeth. Intra Oral examination revealed (fig 1) intrusion of upper left central incisor with vertical fracture of cingulum area and Millers grade II mobility. Considering the unfavorable condition of the tooth, patient was informed that the prognosis was bad and if treatment with flexible acrylic splint could not stabilize the tooth then next option would be extraction of the particular tooth. Written informed consent was taken from the patient and treatment was carried out. We took the radiograph of the particular area. In fig.2 IOPAR (intra oral periapical radiograph) reveals Ellis \& Deweys' Class III fracture of upper left and Class II fracture of upper right central incisor. Widening 


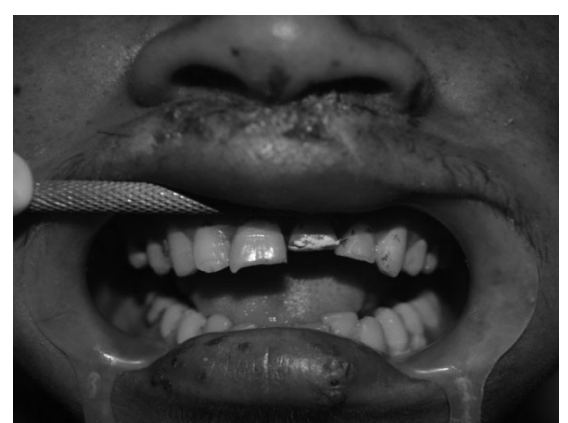

Fig 1. Clinical view during 1st visit.

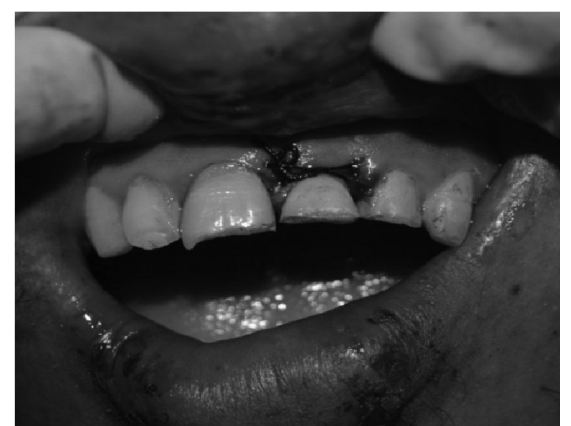

Fig 4. Sling Sutures in position.

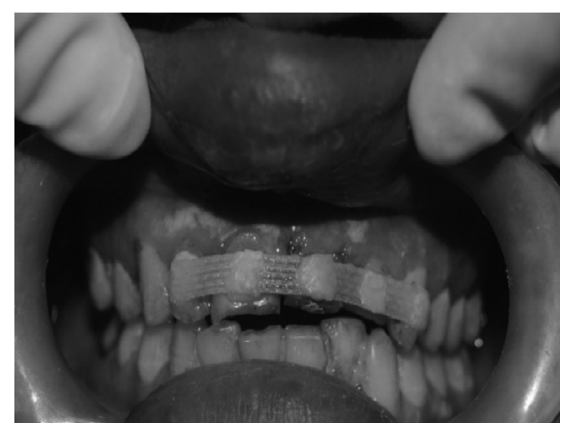

Fig 7. 1 week after 1st visit. Sling suture removed.

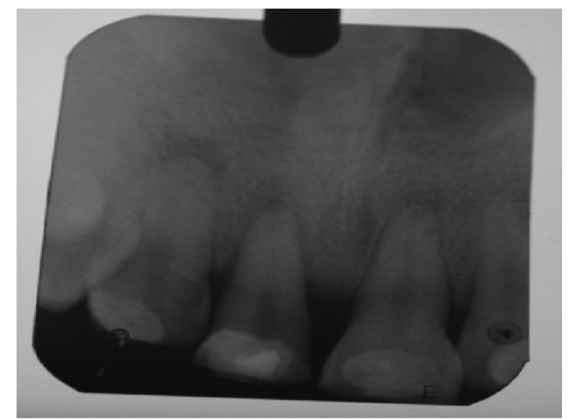

Fig 10. IOPAR taken after 1 month.

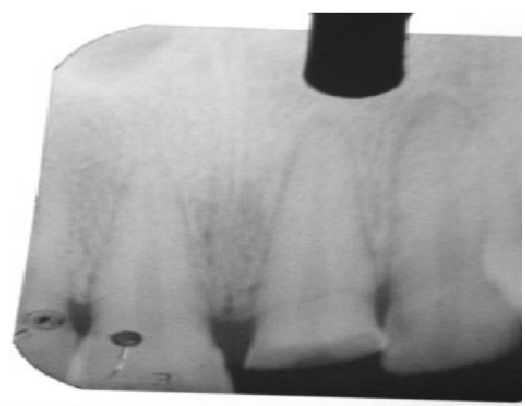

Fig 2. IOPAR taken on 1st visit - Fig 3. After surgical extrusion of upper left preoperative. central incisor to the level of right central.

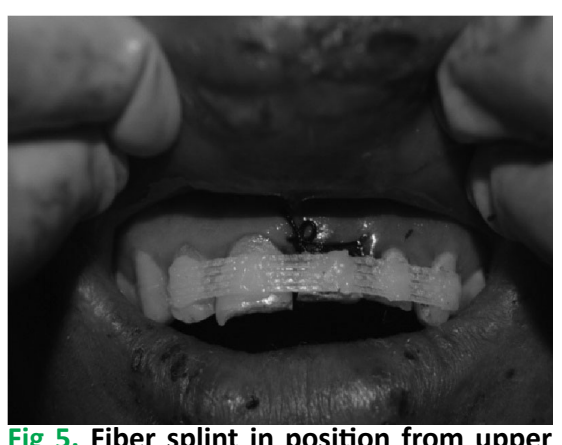

Fig 5. Fiber splint in position from upper Fig 6. Radio opacity is seen in the root right lateral incisor to upper left canine.

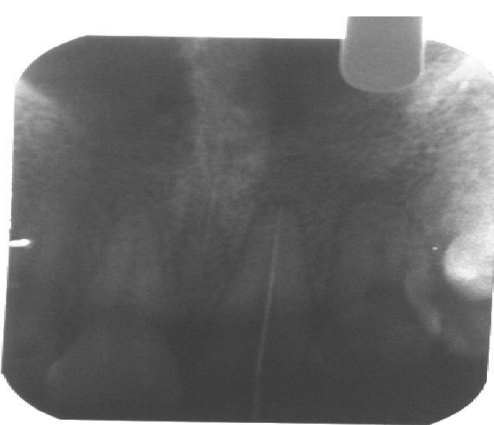
apices.

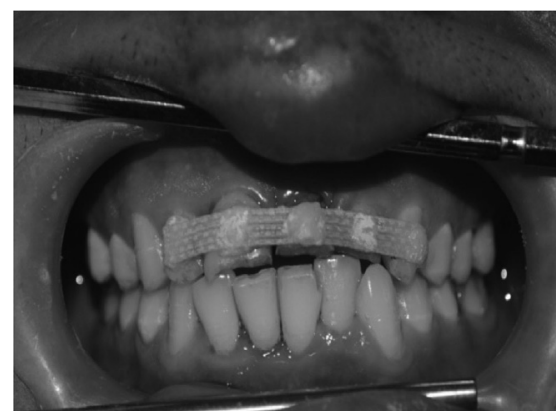

opening.

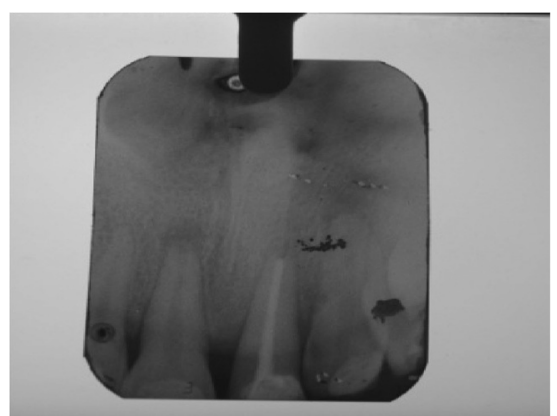

Fig 11. 3rd month radiograph.

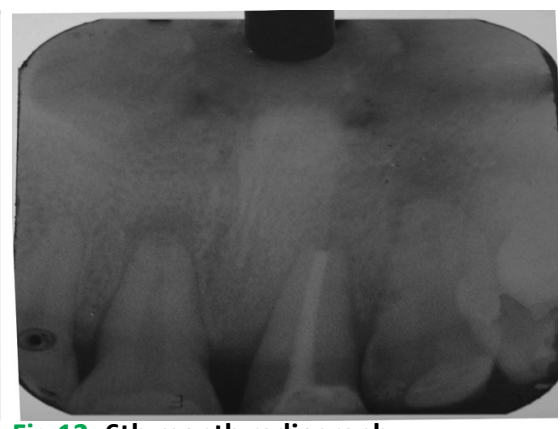

Fig.12. 6th month radiograph.

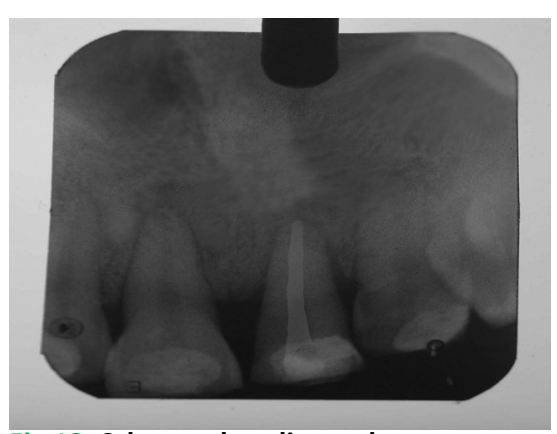

Fig 13. 9th month radiograph. 
of periodontal ligament and periapical radiolucency of upper right and left central incisor is seen. After scaling, infra-orbital and incisive nerve block on the both side was given to anesthetize the maxillary anterior area. Intentional extrusion of the upper left central incisor was done so that it is in the level to right central incisor (fig.3). Extrusion sling suture is placed around upper left central incisor to stabilize near cervical area and to approximate the investing tissues for healing in primary intension (fig 4). After the stabilization of the tooth, etching was done with $37 \%$ phosphoric acid from upper right lateral incisor to upper left canine for 30 seconds, teeth were dried, bonding agent was applied and light cured for 30 seconds on each tooth. Composite was placed and flexible acrylic fiber was placed on middle portion of the tooth and light cured for 60 seconds as seen in (fig.5). After completion of entire clinical procedure post-operative radiograph was taken in which about $3 \mathrm{~mm}$ of tooth has been extruded which can be seen in (fig.6). This radiograph was used as baseline radiograph for measuring the alveolar bone regeneration radiographically.

In second visit after a week patient was recalled for suture removal. Marked reduction in mobility was demonstrated on particular tooth. Oral hygiene became worse than previous visit due to limitations in oral hygiene performance (fig 7). After suture removal scaling was performed and referred the patient to department of endodontics for emergency access opening (fig 8). Patient was recalled for soft tissue evaluation and oral hygiene examination after a month, in his third visit there was still inflammed interdental and marginal gingival in relation to maxillary upper incisor. Patient was instructed to continue with chlorhexidine and recalled after 15 days for evaluation. In 4th visit inflammation of the gingiva was reduced (fig.9) and mobility was almost nil. Radiograph showed initial trabecular pattern formation in the periapical area (fig.10). Patient was recalled after a month with completed root canal procedure to evaluate bone healing. Radiographic evaluation was done after a month which was a three month evaluation from the procedure it showed widening of PDL space and trabecular pattern was dense compared to the IOPAR taken 45 days back (fig 11). Similar IOPAR was taken every three months interval to know the bone healing in $6^{\text {th }}$ and $9^{\text {th }}$ month (fig 12 and 13). Those radiographs showed marked increase in bone density in the periapical area of extruded tooth. PDL space was not violated nor there was widening. Root resorption was not appreciated.

\section{DISCUSSION}

The large number of accidental injuries with multi-organ trauma, necessity for life saving, and the lack of dental instruments in the emergency and operating rooms, may lead the general medical practitioner or surgeon to ignore dental trauma or postpone dental treatment. In above case we have treated the similar intruded teeth using extrusion splint technique and evaluated for nine months, as a result good bone healing was obtained. When the tooth was initially extruded and splinted there was no periapical bone support, but within a month time bone healing has been started and noticed radiographically. There was constant improvement in the periodontal ligament space and periapical bone in interval of three and six months. Periapical bone was prominent with regular trabecular pattern compared with the initial radiograph by the end of nine months. There was no sign of ankylosis, dull sound on vertical and horizontal percussion which can be attributed to dehydration of tooth as a result of avascular and nonvitality. After an injury which causes tooth mobility at the socket or total avulsion, there is damage to the periodontal ligament, cementum layer, and blood vessels that supply blood to tooth pulp. If the tooth is out of socket prompt tooth re-implantation and fixation are most important to prevent future complications. ${ }^{13}$ Avulsed teeth should be maintained in a storage medium such as milk, Viaspan, Hanks balanced salt solution (HBSS), saliva, and saline. ${ }^{14}$

The healing potential of bone is influenced by biochemical, cellular, hormonal and pathological mechanisms. Healing of bone occurs in three phase: Reactive Phase involves inflammatory reaction and granulation tissue formation, Reparative Phase involves cartilage callus formation and lamellar bone deposition, Remodeling phase bone is remodeled to original contour. This results in formation of granulation tissue, ingrowth of vascular tissue, and migration of mesenchymal cells. The primary nutrient and oxygen supply of this early process is provided by the exposed cancellous bone and muscles. As vascular ingrowth progresses, a collagen matrix is laid down while osteoid is secreted which leads to the formation of a soft callus around the repair site and ossifies, forming a bridge of woven bone between the fracture fragments. If proper splinting of teeth is not done, ossification of the callus may not occur. Bone remodelling is a highly coordinated process of bone resorption and formation in which osteoclasts, osteoblasts and osteocytes are necessary. It occurs over several weeks and is performed by clusters of bone resorbing osteoclasts and bone forming osteoblasts arranged within temporary anatomical structures known as "Basic Multicellular Unit" (BMUs). Megakaryoctes enhance osteoblast proliferation and differentiation, express RANKL and OPG and secrete an unknown soluble anti-osteoclastic factor. During the socket healing process, pluripotent and totipotent cells of periodontium are incorporated by an integrated process in which old necrotic bone is slowly resorbed and replaced with new viable bone. This incorporation process is termed "creeping substitution." ${ }^{15}$

Splinting done in case of traumatized tooth has various advantages, it preserve tooth, enhance periodontal healing and bone healing. But, in course of time extruded tooth can have bone loss and undergo ankylosis if immediate root canal treatment is not performed. Some precautions should 
be taken during this extrusion splint procedure such that teeth should not be ankylosed, its supporting structures should be preserved. The most common consequence of trauma is avulsion of tooth, during this there are more chances of tooth getting contaminated. In conditioning of the tooth parallel to regular root canal treatment it is immersed in $2.4 \%$ sodium fluoride solution $(\mathrm{pH} 6.5)$ for 20 minutes. Root surface is then rinsed with saline. After invitro obturation of root canal with gutta-percha, teeth were then left overnight in $3 \mathrm{~g}$ Amoxycillin made up to $50 \mathrm{ml} .{ }^{16}$ Vitality of the tooth can be compromised rather than compromising its surrounding structures. It is widely recommended for surgical reentry in the periapical area to evaluate the quality of bone formed after extrusion splint with adequate time for bone healing. Further histological and clinical studies are required in this technique and quality of periodontium is appraised so that this proficiency can be used in regular basis and avoiding least preferred ankylosis.

\section{REFERENCES}

1. Balcerczyk A, Pirols L. Therapeutic potential of activators and iBijella MFTB. Estudo de traumatismo em incisivos permanantes de escolanes. Brasileiros de Bauru-Estado de Sa o Paulo: Facultade de Odontologie de Baoto; 1972.

2. Zadik D, Fuks A, Eidelman E, Choseck A. Traumatized teeth: two year results. J Peded 1980;4:116-23.

3. Harlamb SC, Messer HH. Endodontic management of a rare combination (intrusion \& avulsion) of dental trauma. Endod Dent Traumatol 1997; 3: 42-6.

4. Barrett EJ, Kenny DJ. Avulsed permanent teeth: a review of the literature and treatment guidelines. Endod Dent Traumatol 1997; 13: 153-63.

5. Trope M. Clinical management of the avulsed tooth: present strategies and future directions. Dent Traumatol 2002;18:1-11.

6. Trope M, Chivian N, Sigurdsson A, Vann WF. Traumatic injuries. In: Cohen S, Burns RC, editors. Pathways of the pulp, 8th edn. St. Louis, MO: Mosby; 2002. p. 636-45.

7. Andreasen JO. Etiology and pathogenesis of traumatic dental injuries. A clinical study of 1,298 cases. Scand J Dent Res 1970;78:329-42.

8. Down C. The treatment of permanent incisor teeth of children following traumatic injury. Aust Dent J 1957;2:9-24.

9. Gabris K, Tarjan I, Rozsa N. Dental trauma in children presenting for treatment at the Department of Dentistry for Children and Orthodontics, Budapest, 1985-1999. Dent Traumatol 2001;17:103-8.

10. Bakland LK. The practising endodontist's approach to traumatic dental injuries. J Endodon 1996;22:440-1.

11. Josell Sd. Evaluation, diagnosis and treatment of the traumatized patient. Dent Clin North Am 1995;39:15-51.

12. Lin S, Zuckerman O, Fuss Z, Ashkenazi M. New emphasis in the treatment of dental trauma: avulsion and luxation. Dent Traumatol 2007;23:297-303.

13. Artisuk A, Gargiulo AV Jr. Incisal edge splint - a case report. Periodontal Case Rep 1982;4:3-4.

14. Teasdale G, Murray G, Parker L, Jennett B. Adding up the Glasgow Coma Score. Acta Neurochir Suppl (Wien) 1979;28:13-6.

15. Kaufman $\mathrm{HH}$, Jones $\mathrm{E}$. The principles of bony spinal fusion. Neurosurgery 1989;24: 264-270.

16. Duggal MS, Toumba KJ, Russell JL, Paterson SA. Replantation of avulsed permanent teeth with avital periodontal ligaments: case report. Endod Dent Traumatol 1994; 10: 282-285. 